REVISTA CHILENA DE LITERATURA

Noviembre 2008, Número 73, 225 - 236

\title{
BORGES Y EDUARDO GUTIÉRREZ: UNA LECTURA MATRERA DE LA GAUCHESCA ${ }^{1}$
}

\author{
Carlos Hernán Sosa \\ Universidad Nacional de Salta \\ chersosa@gmail.com
}

A la memoria de Alicia Chibán, devota de Borges

"Eduardo Gutiérrez (cuya mano escribió treinta y un libros) ha muerto, quizá definitivamente. Ya las obras 'del renombrado autor argentino' ralean en los quioscos de la calle Brasil o de Leandro Alem. Ya no le quedan otros simulacros de vida que alguna tesis de doctorado o que un artículo como este que escribo: también, modos de muerte".

Jorge Luis Borges. "Eduardo Gutiérrez: escritor realista".

\section{INTROITO}

Los comentarios sobre Jorge Luis Borges en estas notas tuvieron en su origen, a ciencia cierta, dos inspiraciones. Ante todo, debo aclarar que por primera vez llegué a la sinuosa relación que Borges mantuvo con la tradición gauchesca a través de Eduardo

1 Una primera versión de este trabajo fue presentada en el "Homenaje a Jorge Luis Borges. A 20 años de su muerte (1986-2006)", encuentro organizado por el Instituto de Investigación de Literatura Argentina e Hispanoamericana "Luis Emilio Soto", de la Facultad de Humanidades de la Universidad Nacional de Salta. El mismo se realizó en la ciudad de Salta, Argentina, los días 16 y 17 de noviembre de 2006. 
Gutiérrez; aún más, como me interesaba revisar la producción folletinesca de Gutiérrez, me entusiasmaron los comentarios laudatorios de un autor hiperconsagrado sobre otro menoscabado y casi olvidado. Esa primera sensación: la de un contacto hasta cierto punto "sacrílego" o "promiscuo", entre la luz enceguecedora y las sombras prescindibles, es decir entre lo canónico y lo marginal, propició mis primeras búsquedas; de paso venía a confirmar aquello que Enrique Pezzoni formulara, en un texto ya clásico: presentar un comentario de crítica literaria, en sus palabras oír el concierto de las voces del texto, en última instancia no es más que ensayar otro modo de hacer autobiografía ${ }^{2}$.

Ya transitando mis intereses por el tema, la constatación de una paradoja reforzó, por segunda vez, mi curiosidad; Borges repitió hasta el hartazgo, y quizás con mayor precisión en uno de sus libros, El Martín Fierro, escrito en colaboración con Margarita Guerrero $^{3}$, una firme aversión por el texto de José Hernández que puede sintetizarse en esta cita, donde estratégicamente anticipaba refutaciones a toda posible disidencia:

Asesino, pendenciero, borracho, no agotan las definiciones oprobiosas que Martín Fierro ha merecido; si lo juzgamos (...) por los actos que cometió, todas ellas son justas e incontestables. Podría objetarse que estos juicios presuponen una moral que no profesó Martín Fierro, porque su ética fue la del coraje y no la del perdón. Pero Fierro, que ignoró la piedad, quería que los otros fueran rectos y piadosos con él y a lo largo de su historia se queja, casi infinitamente (El Martín Fierro 110).

Frente a esta tesitura aparentemente insobornable, clausurada sobre las discutibles idoneidades morales del mayor héroe nacional de la literatura argentina, formuló, por el contrario, comentarios elogiosos sobre Juan Moreira, la más famosa novela por entregas de Gutiérrez ${ }^{4}$ :

Ciertas peleas de Gutiérrez son admirables. Recuerdo una, creo que la de Juan Moreira y Leguizamón. Las palabras de Gutiérrez se me han borrado; queda la escena. A puñaladas pelean dos paisanos en una esquina de una calle de Navarro. Ante los hachazos del otro, uno de los dos retrocede. (...) En la otra esquina, el primero hace espalda en

2 El pasaje completo del texto de Enrique Pezzoni es el siguiente: "El crítico recorta, ordena, de algún modo decide los sentidos del texto. (...) El crítico oye las voces del texto, elige unas a expensas de otras, las une por simpatías y diferencias a las que oye surgir de otros textos. Ese concierto que organiza es una literatura (de un momento, de un espacio) y también es la literatura" (7).

3 Para un análisis de las numerosas estrategias de lectura del texto de José Hernández, que Borges explota en este libro, pueden consultarse los artículos de Mónica Bueno y Raúl Dorra.

${ }^{4}$ Una revisión de las numerosas alusiones a Eduardo Gutiérrez y a sus textos en la obra de Borges, y sus significaciones posibles, puede leerse en el libro de Daniel Balderston, Borges: realidades y simulacros. Varios de nuestros planteos guardan deudas con estos estudios, siempre rigurosos, que Balderston ha realizado sobre el corpus borgeano. 
la pared rosada del almacén. Ahí el otro, lo mata. Un sargento de la policía provincial ha visto ese duelo. El paisano, desde el caballo, le ruega que le alcance el facón que se le ha olvidado. El sargento, humilde, tiene que forcejear para arrancarlo del vientre muerto... (...) ¿no es memorable esa invención de una pelea caminada y callada? ¿No parece imaginada para el cinematógrafo? (Obras Completas, T. IV, 277).

Menos redimible que Fierro, el itinerario de vida de Juan Moreira - o el de Hormiga Negra, otro de los héroes de Gutiérrez admirado por Borges-podría persuadir con mayor convicción sobre los motivos morales que lo llevaron a descalificar al protagonista del poema de Hernández. Evidentemente, ante circunstancias similares la óptica de Borges valida posiciones contrarias que apuestan por una lectura tendenciosa de los autores gauchescos rioplatenses; desde un favoritismo que ya bendice el oportuno recuerdo de Borges, donde la mesa de escrutinio con la cual chocó el puntero político Leguizamón para recibir la muerte, en la novela escrita por Gutiérrez, se trastoca en "la pared rosada del almacén”, en un ícono del fervor porteño de Borges ${ }^{5}$.

Este trabajo es un intento por desmotar las estrategias de interpretación sobre las cuales reposa la incisiva lectura de Borges, trata de indagar sobre cuáles fueron las utilidades de vinculación con la producción de Gutiérrez y qué factores justificaban que un escritor, que dedicó su vida a la literatura y a la construcción de una cuidadosa "imagen de autor" que -aunque matizada por calculadas incongruencias- se postuló monolíticamente en su práctica escrituraria como exponente de una apabullante erudición, de la exhibición de un emporio estilístico matemáticamente irreprochable, con sus estantes de exquisiteces retóricas y su vitrina de relucientes etimologías, decidiera sin embargo validar al mercenario de la literatura; aquel a quien los críticos literarios habían sepultado bajo una lápida denigratoria, porque como auténtico "primitivo" no pudo generar una obra de calidad atendible, según el ejemplar dictamen condenatorio de Ricardo Rojas: "En la superficialidad del modelado, en la pobreza del color, en la vulgaridad del movimiento, y, sobre todo, en la trivialidad del lenguaje (...) es muy escaso el interés artístico que estas obras [los folletines de Eduardo Gutiérrez] presentan en su composición" (587) 7 .

5 Este episodio, que narra uno de los primeros "enfrentamientos electorales" de Moreira, puede releerse, para su comparación con la reescritura operada en la nota de Borges, en uno de los capítulos del folletín de Eduardo Gutiérrez, el titulado "La pendiente del crimen" (Gutiérrez 72-93).

6 Usamos esta categoría según la acepción teórica que propone María Teresa Gramuglio.

7 Otros comentarios desestimadores similares pueden encontrarse, por ejemplo, en Ernesto Quesada y Roberto Giusti. Como óptica superadora de estas perspectivas condenatorias, existe una línea de revisión crítica de la obra de Gutiérrez y de la tradición cuestionadora que ha recibido, para ampliar este punto puede leerse: Jorge B. Rivera, Adolfo Prieto, Josefina Ludmer, Alejandra Laera y Carlos Sosa. 


\section{LA ASTUCIA LECTORA DE LA TRADICIÓN GAUCHESCA}

La primera "utilidad" aleatoria, que Borges explota a partir de la lectura reivindicadora de Gutiérrez, es reforzar su interpretación hostil al Martín Fierro. Borges, quien empeñosamente no desperdició oportunidad para la censura moral del héroe de Hernández, lo reinventó como un personaje de transición: de la gauchesca rioplatense tradicional -es decir la anterior a Hernández- al compadrito orillero porteño de la transición al siglo XX. En este sentido, fue un acierto indiscutible aproximarlo a los héroes de Gutiérrez, criaturas moldeadas en la tradición gauchesca pero cuyos desempeños pulidos por las urgencias económicas del folletín finisecular-donde la cara menos refulgente de la modernidad exhibía el crimen rentado por encargo, la violencia política y los desamparos institucionales-, respetaban a pie juntillas el rol de auténticos cuchilleros -a veces, el de improvisados malandrines. Sobre este punto expresó Borges, con indiscutible verdad:

Para nosotros, el tema del Martín Fierro ya es lejano y, de alguna manera exótico; para los hombres del mil ochocientos setenta y tantos, era el caso vulgar de un desertor, que luego degenera en malevo. Buena prueba de ello es que Eduardo Gutiérrez abundó luego en argumentos análogos, sin que a nadie se le ocurriera pensar que éstos procedían del Martín Fierro (El Martín Fierro 97) ${ }^{8}$.

Es precisamente esta visión "orillera" la que impone al releer las acciones de Martín Fierro. Destaca, por ejemplo, las actitudes pendencieras de Fierro, su indiscutible frialdad de asesino, al comentar el episodio donde mata al moreno, amparado en el deshonor: "Hemos escrito que lo asesina y no que lo mata, porque el insultado que se deja arrastrar a una pelea que otro le impone, ya está dejándose vencer por ese otro" ( $E l$ Martín Fierro 55). Descubre también actitudes hipócritas en el personaje, pues luego de burlarse del hermano del moreno que había asesinado, aconsejó a sus hijos -dirá Borges "untuosamente"- lo que en realidad no sentía; resuenan pues, farsantes, los versos de la admonición filial ejemplificadora del héroe: "El hombre que no mate al hombre/ ni pelee por fantasía./ Tiene en la desgracia mía/ un espejo en qué mirarse" (El Martín Fierro 90-91) ${ }^{9}$. El crítico advierte, además, que la simiente maleva, por su genuina y

8 Dirá Borges, en otro pasaje igualmente significativo: "Eduardo Gutiérrez, autor de folletines lacrimosos y ensangrentados, dedicó buena parte de sus años a novelar al gaucho según las exigencias románticas de los compadritos porteños" (Obras Completas, T. IV, 278).

9 En una de sus ficciones continuadora del libro de Hernández, "El fin”, Borges reitera el énfasis al retratar la actitud hipócrita del personaje, en el sentido de que dice cosas que, evidentemente, no siente, pues no es en ningún momento fiel a ellas; por ejemplo, aconseja a los hijos no matar, pero luego se presenta al duelo con el moreno con ese propósito: "-Le di buenos consejos -declaró-, que nunca están de más y no cuestan nada. Les dije entre otras cosas que el hombre no debe derramar la sangre del hombre" (Obras Completas, T. I, 520), el subrayado es mío. En el caso de otro relato que reescribe el Martín Fierro, la "Biografía de Tadeo Isidoro Cruz (1829-1874)", abundan asimismo las designaciones de "desertor", 
díscola naturaleza, se proyecta vivamente en el hijo segundo de Fierro, de quien dirá en tono de sentencia final que "habla menos como paisano que como compadrito letrado" (El Martín Fierro 81).

Pero quizás el modo más evidente en que Borges traba esta filiación deliberada entre Gutiérrez y Hernández, con el fin de sustentar su lectura personal de la gauchesca, asoma, de manera insolente, al analizar el duelo entre Fierro y el indio, narrado en un pasaje del comienzo de La Vuelta de Martín Fierro (cantos VII-IX). Dice Borges, en su comentario del episodio: "Silenciosa, empieza la tremenda pelea. Fierro maneja el cuchillo; el indio las boleadoras de piedra", y coloca luego al final de la frase una nota al pie donde, como al pasar, establece una comparación que, aunque intencionadamente marginal, no deja de ser reveladora: "En los últimos años del siglo XIX, Guillermo Hoyo, más conocido por Hormiga Negra, matrero del partido de San Nicolás, peleaba (según testimonio de Eduardo Gutiérrez) con boleadoras y cuchillo" (El Martín Fierro 75).

Dos estrategias me resultan relevantes en este entramado cincelado por la lectura de Borges; en primer lugar el fingido pudor que lo lleva a sugerir, después de haberlo divulgado hasta el cansancio, que Martín Fierro peleaba como los gauchos matreros y cuchilleros retratados por Gutiérrez; y en segundo lugar, la que parece ser más relevante, el gesto implícito en la propia manipulación de lectura, que cifra en muchos sentidos el modo provocativo de relacionar a Hernández con Gutiérrez que venimos sugiriendo. La estrategia impulsada en esta "azarosa" e "imperceptible" nota al pie nos indica, a modo de conclusión, que es posible leer el texto más canónico de los argentinos desde una vinculación con aquello que la tradición literaria ha dejado en los márgenes del olvido. El gesto de Borges, en esta lectura afrentosa, parece guardar entonces un magisterio "peligroso", pues nos demuestra que podemos comprender mejor a Martín Fierro si lo equiparamos con Hormiga Negra: entenderemos al héroe entronizado solo cuando lo intersectemos con las vivencias deshonestas y ensangrentadas de los numerosos -y olvidables- héroescomodines de la producción folletinesca finisecular de vertiente popular ${ }^{10}$.

Esta es, creemos, la lectura pendenciera que hace Borges de la gauchesca, una verdadera matrereada literaria donde relee lo ultracanónico desde la periferia, movimiento

"malevo" y "criminal", que colaboran en la desestimación ética de Fierro. Véase Borges, Obras Completas, T. I, 562-563.

10 En sus consideraciones, Borges, como en otras oportunidades, se anticipaba a algunos planteos que la crítica literaria académica revisaría solo con posterioridad. En este caso, las intersecciones e interdependencias comprobables entre la obra de Gutiérrez y los autores canónicos contemporáneos (los gauchescos como José Hernández, los nativistas como Rafael Gutiérrez o los naturalistas como Eugenio Cambaceres) fueron ensayadas con posterioridad, recién a partir de fines de la década de 1960, en trabajos que hoy nos resultan fundamentales, para aproximarnos al espectro de producción literaria porteña de fines del siglo XIX y para ubicar la participación de Gutiérrez en este campo de producción. Las reconsideraciones, sobre el punto al que hacemos referencia, pueden ubicarse en los trabajos críticos de Jorge B. Rivera, Adolfo Prieto y Alejandra Laera. 
artero con el cual tira filosos agravios que invitan al choque con los defensores de una lectura más tradicional de la literatura argentina, es decir la versión oficial y rioplatense que habían edificado Ricardo Rojas y Leopoldo Lugones, a comienzos del siglo XX, al calor de los efluvios nacionalistas del Centenario. ${ }^{11}$

\section{UNA GAUCHESCA PERSONAL}

Por otra parte, además de lanzarse a la polémica -con Borges siempre suele haber un "además"- el hecho de seleccionar un autor gauchesco donde el elemento orillero resulta más apropiado para desestimar a Hernández no es el único beneficio obtenido; en el fuero personal más íntimo, la situación le reporta ganancias al mismo Borges. Puesto que esta constante apropiación del mundo imaginario, donde reinan el culto al coraje y dictamina el duelo a cuchillo, también apuntala su elección literaria de las orillas porteñas; una construcción estética discursiva que tiene su génesis en la fundación mítica que inventa para Buenos Aires, a partir de sus primeros poemarios y de Evaristo Carriego (1930), y que permanecerá - a veces con cierta latencia- a lo largo de toda su producción. No en vano, entonces, la interpretación que elige para la gauchesca es aquella donde puede trazar fácilmente una tradición literaria dinámica y propicia para su propio proyecto literario ${ }^{12}$.

En este sentido, abundan en su lectura del género el rescate de elementos que, por más accesorios o mínimos que parezcan, son capaces de permitir una vinculación en sintonía con sus intereses literarios personales. Emplea entonces tópicos borgeanos para sistematizar su lectura de toda la tradición gauchesca. En ella organiza, por ejemplo, redes reversibles donde Antonio Lussich, el autor uruguayo de Los tres gauchos orientales, prefigura a Hernández, de modo que "sus diálogos son un borrador ocasional, pero indiscutible, de la obra definitiva de Hernández" (El Martín Fierro 30); al tiempo que este último, sostiene Borges, también debería entenderse como el engendrador de Lussich, puesto que solo ha logrado perdurar en las historias de la literatura hispanoamericana gracias al poeta argentino, por haber sido el precursor de Hernández.

Otro de los tópicos que recupera del género, por mandato íntimo, es el momento revelador y único, "aquel en que el hombre sabe para siempre quien es" (Obras Completas, T. I, 562), un interés que luego reinstalaría como tema en sus continuaciones de la gauchesca -en "El fin" y la "Biografía de Tadeo Isidoro Cruz (1829-1874)"- y también en otros textos como el "Poema conjetural" y la "Historia del guerrero y la cautiva", o

11 Una de las últimas revisiones de la labor "estatal” que cubrieron Lugones y Rojas, durante el Centenario, puede consultarse en el texto de Miguel Dalmaroni.

12 La acepción que Raymond Williams aporta para la noción de "tradición", como un constructo cultural selectivo y dinámico, resulta iluminadora para entender el modo en que Borges reorganiza la tradición gauchesca, con vistas a reencauzar su propio proyecto literario. Para poner a prueba el punto consúltese Raymond Williams. 
incluso, en clave fantástica, surgirá en la misma revelación del soñador-soñado de "Las ruinas circulares", pues todos los protagonistas de estos textos descubren "con alivio, con humillación, con terror" (Obras Completas, T. I, 455) su razón de ser.

Gutiérrez también es una excusa que le permite rearmar una genealogía libresca que va más allá de la gauchesca rioplatense, en una actitud que vuelve a confirmar que Borges hizo lo que quiso en materia de recuperación de autores, amparado tal como lo había justificado en su ensayo "El escritor argentino y la tradición"13, en la actitud irreverente de ser argentino, un sujeto con escasa tradición literaria propia que tenía, como compensación de estas carencias, la posibilidad de disponer de toda la tradición literaria universal.

En este rompecabezas de títulos y escritores, por supuesto, los egregios tomos de la biblioteca inglesa ocupan los estantes privilegiados, por ello no nos extraña que se compare el desafío del moreno en el Martín Fierro con Hamlet -y con Las mil y una noches-, porque encierra también otros escenarios y otros sueños sucesivos (El Martín Fierro 86) -es decir, los que el propio Borges tramará para "El fin"-, o que se afirme que Juan Moreira "es un lujoso personaje de Byron que dispensa con pareja solemnidad la muerte y la lágrima” (Obras Completas, T. IV, 277). Tampoco resulta sorprendente que los elementos positivos que subraya del Martín Fierro, los que rescatan a la obra de Hernández de las caducas aspiraciones de su contexto primero y la depositan para su culto en el altar universal, son aquellos que admiten la vinculación sustancial con el Quijote, otra de las debilidades literarias de Borges ${ }^{14}$.

A pesar de recuperar a Gutiérrez y no negarle un lugar en su biblioteca personal junto a los clásicos universales, es verdad, no seamos ingenuos, cuando Borges sintió la necesidad de reescribir un texto de la tradición gauchesca no pensó ciertamente en Juan Moreira o en Hormiga Negra, eligió sin vacilación continuar al Martín Fierro. Digamos que no existió aquí ningún dilema, sabemos que si no reescribió alguno de los folletines gauchesco-policiales de Gutiérrez ${ }^{15}$ no fue porque Hernández le resultara

13 De este texto, uno de los más representativos sobre los nexos que Borges trabó con la tradición literaria mundial, conservamos una versión taquigráfica, pues constituyó en su origen una clase dictada en el Colegio Libre de Estudios Superiores; dicha versión se publicó luego en sus Obras Completas (T. I, 267-274), como parte de Discusión, libro de ensayos que había sido publicado anteriormente en 1932.

14 La cita que expresa esta correlación, de manera acabada, es la siguiente: "El Quijote se ejecutó para reducir al absurdo las novelas de caballerías, pero es fama que excede infinitamente ese propósito paródico. Hernández escribió para denunciar injusticia locales, pero en su obra entraron el mal, el destino y la desventura, que son eternos" (El Martín Fierro 41). Para un análisis de la presencia de Cervantes en el corpus borgeano, consultar el trabajo de Ana María Barrenechea.

15 Para ser sinceros, existe otra recuperación de la obra de Gutiérrez en uno de los Cuentos breves y extraordinarios, que el autor compiló en complicidad con Adolfo Bioy Casares. Se trata del texto firmado por Fra Diávolo, "Vistazos críticos a los orígenes de nuestro teatro", 
más reconciliable con su lectura sobre el género, sino porque, amigo de la querella, siempre advirtió que el gesto urticante consistía en poner su pluma al servicio de retratar a Martín Fierro como "el caso individual de un cuchillero de 1870" (El Martín Fierro 100), valiéndose de los condimentos hiperbolizados del compadrito, que aportaban en abundancia los amistosos novelones de Gutiérrez ${ }^{16}$. Por otra parte, celoso guardián $-\mathrm{y}$ progenitor- de su ilustre prosapia literaria, Borges tramó una genealogía personal donde acreditar filiaciones con lo más genuino e indiscutible de la tradición literaria nacional argentina tenía sentido, pues ella se constituía en soporte de buena parte de su práctica escrituraria; y ante tamaña urgencia, como suele ser frecuente en toda buena familia, las simpatías plebeyas por Gutiérrez se acababan y el enfrentamiento, apenas rebelde, ante el abuelo Hernández se reencauzaba.

\section{EL GOCE DE LA LECTURA}

La siguiente gran "utilidad" que representa la recuperación de Gutiérrez para Borges no se vincula, creemos, con las polémicas literarias y el razonado lugar de las argumentaciones, donde esgrimir "verdades" sobre los otros es indiscutiblemente salvaguardar mis proyectos y obsesiones personales. En este caso, su figura le resulta apropiada para defender una concepción particular de la lectura, del placer por la lectura, que la delimitaría como una experiencia trascendental que Gutiérrez parece haber garantizado sobradamente, durante las horas dedicadas a su incansable práctica como lector.

En "La fruición literaria", uno de sus tempranos ensayos de juventud, voluntariamente olvidado luego, en un tomo del cual renegaría -El idioma de los argentinos, publicado por primera vez en 1928-, Borges reorganizaba una de las primeras versiones de su biblioteca personal, desde el placer unificador de la lectura, mediante una entusiasta enumeración sin comas que, superficialmente, parecía anticipar las enumeraciones

editado originalmente como nota en un número de la revista Caras y Caretas del año 1911, que Borges y Bioy publican bajo el nuevo título de "Otra versión de Fausto". En la misma se pone en escena un juego entre realidad y ficción, motivado por la aparición previa de Hormiga Negra a una representación de la obra que lo tenía como protagonista, amenazando a los Podestá, dueños del circo que montaba la pieza, enojado porque "otro" se hacía pasar por "él” ante el público. La recuperación de la figura de Hormiga Negra puede entenderse como otro homenaje velado a Gutiérrez, y también como un modo de reescritura del personaje, pues la inclusión en la antología de "cuentos extraordinarios" resignifica los sentidos de la nota periodística y las aristas netamente matonescas que tenía el personaje en el folletín de Gutiérrez.

16 Sobre las ficciones borgeanas continuadoras del texto de Hernández existe abundante bibliografía, solo recomendamos aquí algunas lecturas, movilizadas por diversos intereses: Pedro Luis Barcia, Jaime Alazraki, Estela Cédola, Josefina Ludmer (El género gauchesco) y Beatriz Sarlo. 
caóticas de su futura poesía. En el acopio de nombres, sorprende encontrar a Gutiérrez ocupando un lugar destacado:

Sospecho que los novelones policiales de Eduardo Gutiérrez y una mitología griega y el Estudiante de Salamanca y las tan razonables y tan nada fantásticas fantasías de Julio Verne y los grandiosos folletines de Stevenson y la primera novela por entregas del mundo: las 1001 Noches, son los mejores goces literarios que he practicado ( $E l$ idioma de los argentinos 87) ${ }^{17}$.

Como podemos ver, estas apreciaciones promueven una reivindicación de la lectura como placer, que va de la mano de una anécdota de las numerosas que pueblan el mundo, ya indudablemente mítico, gestado en torno de la figura de Borges. En una entrevista televisiva, Borges eternizó la idea de que solo deben leerse los libros que resultan placenteros y que deben abandonarse, para no perder nuestro tiempo, aquellos que no lo son, a pesar de lo muy clásica o consagrada que fuera la fama que arrastrasen. En ambas consideraciones no parece funcionar la acepción de placer que acuñaron algunos escritores y críticos literarios, como aquella que exige del lector una participación activa, reticente, cuestionadora y en última instancia "completiva" del texto literario, sino que más bien despunta en ellas otra connotación, aquella que nos eriza la gula y la distensión lujuriosa del dejarse llevar por la lectura, seducidos por los hilos atrapantes de la intriga, por más coercitiva o "hembra" que resulte la experiencia, al decir machista de Julio Cortázar" Podemos advertir también que la circunstancia ya no es indicadora sobre cómo leer a Gutiérrez o cuál es la genealogía literaria donde deberíamos interpretarlo, pues el razonamiento suspende todas estas inquietudes en función de señalar una experiencia gratificante particular de lectura que nos enseña cómo debemos leer habitualmente.

Este modo personal de acercarse al autor es también una forma muy solapada pero contundente que Borges promueve para hablar de sí mismo, para defender sus lecturas y para justificar una tutela de sus precursores velados, fervorosamente queridos, que habían sido recluidos, en muchos casos, al margen de las consagraciones literarias académicas; tal es el caso de los fabuladores de aventuras como Robert Louis Stevenson, de correrías marineras como Joseph Conrad o de iterativos duelos criollos como Eduardo Gutiérrez.

17 Para la inserción de este libro de ensayos en el corpus del "primer Borges", son productivas las lecturas de Rafael Olea Franco y Eduardo Romano. La vinculación específica entre Gutiérrez y Stevenson, como dos de los precursores velados de Borges, ha sido trabajada por Daniel Balderston en otro de sus libros dedicados al autor: El precursor velado: $R$. $L$. Stevenson en la obra de Borges.

18 Sugerimos aquí solo dos perspectivas contrapuestas con las cuales debaten los planteos de Borges: la de índole teórica establecida por Roland Barthes, y la que promocionó Julio Cortázar en su propia práctica escrituraria, especialmente a través de Rayuela. 


\section{CODA}

Si empezamos aludiendo a la autobiografía, quizás no resulte inadecuado, para cerrar el círculo y jugar con otro de los más difundidos emblemas borgeanos, concluir estas breves consideraciones volviendo sobre el mismo asunto. Hace varios años, en cierto lejano recinto universitario, un profesor histriónico nos dictaba una clase sobre la escritura autobiográfica, nos instruía en ella sobre el "egotismo", sobre la imperiosa necesidad de hablar de uno mismo, esa especie de "ansia yoyesca" que, si bien puede tomar diversas formas escriturarias, en definitiva él pensaba que podía reducirse a dos actitudes narrativas paradigmáticas, y las enunció a modo de adagio iluminador: "Hay personas que para hablar de sí mismas echan mano al mundo -nos decía-, se regodean soberbias en su inmensidad, es decir que cuando hablan del mundo están hablando de sí mismas; pero hay otras -continuaba, enfatizando el tono para anticiparnos el final- que para hablar del mundo, forzosamente, necesitan hablar de sí mismas, y entonces -concluía efectista, bajando la voz- construyen un yo proteico condenado al rol de fina película que nos transparenta, borroso, el universo".

De este modo, si como dice Borges: Ezequiel Martínez Estrada, riguroso lector de Hernández, en Muerte y transfiguración de Martín Fierro volvió a soñar "enriqueciéndolo de sombra y de vértigo el sueño primario de Hernández"19, entonces el propio Borges, un nuevo y ocasional soñador de Hernández y de Gutiérrez, los ha reinventado en sus comentarios críticos para tomar distancia y para compartir complicidades. En este gesto remoto, el de sacar un libro de los incontables anaqueles de la biblioteca, para releer a Gutiérrez y a Hernández, se reformula en parte la ecuación autobiográfica anterior: si para Borges el mundo puede metaforizarse como una biblioteca infinita, entonces para hablar de ese mundo inquietante que es al mismo tiempo hablar de sí, en un gesto sutilmente ególatra, debe simplemente hablar de cualquier libro -en este caso, fortuitamente, son los volúmenes de la gauchesca rioplatense-; pues, una vez más, tomar un texto de la biblioteca parece ser aquí una estratégica excusa para hablar un poco, a veces mucho, de nosotros mismos.

19 La cita completa del pasaje es ésta: "El Martín Fierro ha sido materia, o pretexto, de otro libro capital: Muerte y transfiguración de Martín Fierro (México, 1948), de Ezequiel Martínez Estrada. Trátase menos de una interpretación de los textos que de una recreación; en sus páginas, un gran poeta que tiene la experiencia de Melville, de Kafka y de los rusos, vuelve a soñar, enriqueciéndolo de sombra y de vértigo el sueño primario de Hernández. Muerte y transfiguración de Martín Fierro inaugura un nuevo estilo de crítica del poema gauchesco. Las futuras generaciones hablarán del Cruz, o del Picardía, de Martínez Estrada, como ahora hablamos del Farinata de De Sanctis o del Hamlet de Coleridge" (El Martín Fierro 102-103). La lectura que Borges emprende en El Martín Fierro debate íntimamente con la que impuso Ezequiel Martínez Estrada, y aspira a poder desbancarla, mediante "su" interpretación del texto de Hernández. 


\section{BIBLIOGRAFÍA}

Alazraki, Jaime. Versiones. Inversiones. Reversiones. El espejo como modelo estructural del relato en los cuentos de Borges. Madrid: Gredos, 1977.

Balderston, Daniel. "Dichos y hechos. Borges y la nostalgia de la aventura". Borges: realidades y simulacros. Buenos Aires: Biblos, 2000. 39-58.

El precursor velado: R. L. Stevenson en la obra de Borges. Buenos Aires: Sudamericana, 1985.

Barcia, Pedro Luis. "Proyección de Martín Fierro en dos ficciones de Borges". José Hernández (Estudios reunidos en conmemoración del centenario de El gaucho Martín Fierro) 1872-1972. La Plata: Universidad Nacional de La Plata, 1973. 209-232.

Barrenechea, Ana María. “Cervantes y Borges.” Para leer a Cervantes. Estudios de literatura española Siglo de Oro. Volumen I. Melchora Romanos, coord., Alicia Parodi y Juan Diego Vila, edit. Buenos Aires: EUDEBA, 1999. 281-290.

Barthes, Roland. El placer del texto. Lección inaugural. México: Siglo XXI, 1982.

Borges, Jorge Luis y Margarita Guerrero. El Martín Fierro. Buenos Aires: Emecé, 2005. El idioma de los argentinos. 1928. Buenos Aires: Seix Barral, 1997. Obras Completas. 4 T. Buenos Aires: Emecé, 1994-1996.

Borges, Jorge Luis y Adolfo Bioy Casares. Cuentos breves y extraordinarios. Buenos Aires: Losada, 1995.

Bueno, Mónica. "Borges, lector de Martín Fierro". Hernández, José. Martín Fierro. Edición crítica de Élida Lois y Ángel Núñez. Buenos Aires: Colección Archivos / Sudamericana, 2001. 635-653.

Cédola, Estela. Borges o la coincidencia de los opuestos. Buenos Aires: EUDEBA, 1986.

Dalmaroni, Miguel. Una república de las letras. Lugones, Rojas, Payró. Escritores argentinos y estado. Rosario: Beatriz Viterbo, 2006. 79-106.

Dorra, Raúl. "Borges, lector del Martín Fierro". Ponencia presentada al "VIII Congreso del CELCIRP”, Universidad de la República, Montevideo, 2002, inédito.

Giusti, Roberto F. "La prosa de 1852 a 1900”. Historia de la literatura argentina. T. III. Rafael Alberto Arrieta, coord. Buenos Aires: Peuser, 1959. 359-438.

Gramuglio, María Teresa. "La construcción de la imagen”. La escritura argentina. Héctor Tizón et al. Santa Fe: Universidad Nacional del Litoral y Ediciones de La Cortada, 1992. 35-64.

Gutiérrez, Eduardo. Juan Moreira. Buenos Aires: EUDEBA, 1961.

Laera, Alejandra. El tiempo vacío de la ficción. Las novelas argentinas de Eduardo Gutiérrez y Eugenio Cambaceres. Buenos Aires: FCE, 2004.

Ludmer, Josefina. "Los Moreira". El cuerpo del delito. Un manual. Buenos Aires: Perfil, 1999. 225-300. 1988.

Olea Franco, Rafael. El otro Borges, el primer Borges. Buenos Aires: FCE, 1993. 
Pezzoni, Enrique. El texto y sus voces. Buenos Aires: Sudamericana, 1986.

Prieto, Adolfo. El discurso criollista en la formación de la Argentina moderna. Buenos Aires: Sudamericana, 1988.

Quesada, Ernesto. “El 'criollismo' en la literatura argentina”. En torno al criollismo. Textos y polémica. Alfredo V. E. Rubione, comp. Buenos Aires: CEAL, 1983. 103-230.

Rivera, Jorge B. Eduardo Gutiérrez. Buenos Aires: CEAL, 1967.

Rojas, Ricardo. Historia de la literatura argentina. Ensayo filosófico sobre la evolución de la cultura en el Plata. 8 T. Buenos Aires: Losada, 1948.

Romano, Eduardo. "Para otro perfil del Borges criollista". Borges. Buenos Aires: Biblioteca del Congreso de la Nación Argentina, 1997. 145-162.

Sarlo, Beatriz. Borges un escritor en las orillas. Buenos Aires: Ariel, 1995.

Sosa, Carlos Hernán. "El '80 y una experiencia de escritura innovadora: el folletín, el periodismo y el uso de las fuentes judiciales en Juan Moreira de Eduardo Gutiérrez". Las tensiones de los opuestos. Libros y autores de la literatura argentina del '80. María Minellono, coord. Buenos Aires: Grupo Editor Latinoamericano, 2004. 87-109.

“Las bondades de un juez 'justo': el enmascaramiento conveniente del folletín (Sobre procesos judiciales y ficciones populares en la Argentina de fines del siglo XIX)". Anclajes. Revista del Instituto de Análisis Semiótico del Discurso. 9/IX (2005): 141-156.

Williams, Raymond. Marxismo y literatura. Barcelona: Península, 1980.

Palabras Clave: Jorge Luis Borges, Eduardo Gutiérrez, tradición gauchesca, Martín Fierro, lectura.

KEY WORDS: Jorge Luis Borges, Eduardo Gutiérrez, gauchesque literary tradition, Martín Fierro, reading. 